\title{
Synthesis and luminescence properties of Pr doped SLS-ZnO glass composite material for red phosphors
}

\begin{abstract}
Praseodymium (Pr) doped SLS-ZnO glass composite material of chemical formula [(SLS $)_{0.5}$ $\left.(\mathrm{ZnO})_{0.5}(\mathrm{Pr})_{\mathrm{x}}\right]$ where $\mathrm{x}=1 \mathrm{wt} \%$ sintered at $600,700,800,900$ and $1000{ }^{\circ} \mathrm{C}$ were prepared by solid state technique. The structure, morphology and luminescence properties have been characterized by X-ray diffraction (XRD), Fourier transform infrared radiation (FTIR), UVVis spectroscopy, photoluminescence spectroscopy (PL), field emission scanning microscopy (FESEM) and energy dispersive X-ray (EDX). The XRD, FTIR and EDX studies reveal the formation of $\mathrm{Zn}_{2} \mathrm{SiO}_{4}$ from SLS-ZnO host lattice. FESEM shown the particle size distribution would lead to a higher packing density by increasing sintering temperatures. The presence of $\mathrm{Pr}^{3+}$ ions into $\mathrm{Zn}_{2} \mathrm{SiO}_{4}$ was confirmed by EDX analysis. The absorption peaks at 360,444 and $616 \mathrm{~nm}$ originate in the UV and visible range were observed by UV-Vis spectroscopy. The PL spectrums with excitation at $444 \mathrm{~nm}$ exhibit two strong red emission peaks at $\sim 613$ and $\sim 637 \mathrm{~nm}$ were attributed to the transition of ${ }^{3} \mathrm{P}_{\mathrm{o}} \rightarrow{ }^{3} \mathrm{H}_{6}$ and ${ }^{3} \mathrm{P}_{\mathrm{o}} \rightarrow{ }^{3} \mathrm{~F}_{2}$. It is found that $\mathrm{Pr}^{3+}$ ions substituted into the host lattice could improve to the luminescence properties with increasing sintering temperatures. These results indicate that Pr doped SLS$\mathrm{ZnO}$ exhibits great potential red phosphors in WLEDs application.
\end{abstract}

Keyword: Synthesis; Luminescence properties; Praseodymium (Pr); SLS-ZnO glass composite material; Red phosphors 